\title{
Rancang Bangun Sistem Kontrol Kipas Angin dan Lampu Otomatis di Dalam Ruang Berbasis Arduino Uno R3 Menggunakan Multisensor
}

\author{
Joni Parhan*, Rahmat Rasyid \\ Jurusan Fisika FMIPA Universitas Andalas \\ Kampus Unand, Limau Manis, Padang 25163 \\ *ciqulofjon@gmail.com
}

\begin{abstract}
ABSTRAK
Telah dilakukan rancang bangun sebuah sistem kontrol kipas angin dan lampu otomatis ruangan. Sistem bertujuan agar pemakaian kipas angin dan lampu menjadi efisien sehingga dapat menghemat penggunaan energi listrik dan juga menciptakan kenyamanan bagi pengguna ruangan. Sistem bekerja apabila ada orang di dalam ruangan. Sistem terdiri dari sensor PIR untuk mendeteksi manusia, sensor DHT11 yang berfungsi sebagai pendeteksi suhu dan kelembaban relatif, dan sensor LDR untuk mendeteksi intensitas cahaya di dalam ruangan. Mikrokontroler Arduino Uno R3 yang berfungsi sebagai pengolah data dari masukan sensor, mengatur kerja relay, dan LDC untuk menampilkan data sensor. Sistem kontrol kipas angin dan lampu otomatis menunjukan sensor PIR HCSR501 dapat mendeteksi objek manusia pada jarak maksimum $6 \mathrm{~m}$ tepat di depan sensor. Sensor DHT11 dapat mendeteksi perubahan temperatur di dalam ruangan dengan nilai error rata-rata $1,87 \%$ dan kelembaban relatif dengan error 5,98 \%. Sensor LDR dapat mendeteksi perubahan intensitas cahaya.

Kata kunci: intensitas cahaya, kelembaban relatif, otomatis, sensor, temperatur
\end{abstract}

\section{ABSTRACT}

An automatic room fan and light control system has been designed and implemented. The system aims to make the usage of fan and light become efficient so as to save the use of electrical energy and also create comfort for the user room. This system will work when the are people in the room. The system consists of a PIR sensor for human detection, a DHT11 sensor that acts as a detection of temperature and relative humidity, and an LDR sensor for light in the room. Arduino Uno R3 microcontroller that functions as a data processor from the sensor input, adjusts the working relay that functions as an automatic switch. LCD displays sensor data. Result shows that the PIR sensor HCSR501 can detect human object at a maximum distance of $6 \mathrm{~m}$ directly in front of the sensor. The DHT11 sensor can detect changes in temperature with an avarage error of $1.87 \%$ average temperature measurement and an average relative humidity measurement error of 5.98\%. The LDR sensor can detect changes in light intensity.

Keywords:light intensity, relative humidity, automatic, sensor, temperature

\section{PENDAHULUAN}

Penggunaan energi listrik sebagai sumber daya utama untuk peralatan elektronik di Indonesia terus meningkat seiring meningkatnya jumlah penduduk sebesar $1,3 \%$ per tahun dan laju pertumbuhan ekonomi sebesar 6,8\% per tahun. PT PLN (2015) menyatakan perkiraan kebutuhan tenaga listrik nasional diperkirakan akan tumbuh rata-rata sebesar 8,7\% per tahun, sementara penambahan kapasitas pembangkit hanya mengalami perkembangan rata-rata $4,3 \%$ per tahun.

Penggunaan energi listrik sering kali bersifat di luar kebutuhan, seperti lampu hidup dan kipas angin hidup namun tidak ada penghuni di dalam ruangan. Berdasarkan Instruksi Presiden Republik Indonesia Nomor 10 Tahun 2005 tentang penghematan energi, maka diharapkan setiap masyarakat pemakai listrik dapat menghemat penggunaan energi listrik di rumah ataupun tempat kerja masing-masing. Cara penghematan energi dapat dilakukan dengan melakukan kontrol terhadap alat elektronik agar dapat meminimalisir penggunaan energi listrik di luar kebutuhan. Alasan inilah perlu dirancang sebuah sistem kontrol otomatis untuk perangkat elektronik untuk penghematan energi listrik.

Otomo (2013) telah melakukan penelitian untuk sistem otomatisasi kontrol lampu berdasarkan keberadaan orang di dalam ruangan dengan menggunakan sensor passive infrared (PIR). Jarak waktu respon dari sensor PIR KC7783R ini untuk mendeteksi objek adalah 5,37 detik. Jarak maksimum yang dapat dideteksi sensor PIR adalah 4,3 meter pada sudut $0^{\circ}$ (lurus dari depan sensor), dan 2 meter pada sudut $30^{\circ}$ (ke kiri dan ke kanan). Sensor ini membutuhkan waktu pemanasan selama 25,52 detik. Pada penelitian ini lampu ruangan tetap hidup meskipun 
cahaya alami dari luar ruangan mencukupi untuk menerangi ruangan sehingga unsur penghematan listrik kurang terpenuhi.

Kurniawan dkk. (2013) telah melakukan penelitian mengenai sistem penerangan rumah otomatis dengan sensor cahaya berbasis mikrokontroler. Mikrokontroler yang digunakan adalah AVR ATMega16. Mikrokontroler berfungsi untuk memproses sinyal masukan dari sensor cahaya sebagai komponen umpan balik, kemudian menghasilkan keluaran yang ditunjukan pada aktuator dalam hal ini adalah relay. Sensor cahaya yang digunakan adalah sensor LDR. Hasil akhir penelitian ini adalah sistem penerangan otomatis untuk mengendalikan lampu berdasarkan pengukuran intensitas cahaya oleh sensor di sekitar lampu yang kemudian dikonversi menjadi nilai ADC (Analog to Digital converter). Lampu menyala secara otomatis jika nilai ADC 0 - 60 dan sebaliknya lampu mati secara otomatis jika nilai ADC $61-102$. Lampu tetap hidup meskipun tidak ada orang di dalam ruangan.

Desyantoro dkk. (2015) membuat pengendali peralatan elektronik dalam rumah secara otomatis. Sistem terdiri dari sensor PIR yang berfungsi untuk mendeteksi objek manusia, sensor LM35 yang berfungsi untuk mendeteksi temperatur, dan sensor LDR berfungsi sebagai sensor cahaya, mikrokontroler ATMega16 sebagai pengendali jalannya sistem dari pembacaan sensor untuk menampilkan data sensor pada LCD dan mengatur kontak relay untuk menghidupkan dan mematikan listrik. Sistem pengendali peralatan elektronik dalam rumah secara otomatis menunjukan sensor LDR dapat membedakan gelap dan terang, sensor suhu LM35 dapat mendeteksi temperatur dalam ruangan dengan toleransi kesalahan pembacaan kurang lebih $2^{\circ} \mathrm{C}$, dan sensor PIR dapat mendeteksi pergerakan manusia sejauh 5 meter. Pada penelitian ini sensor yang digunakan yaitu LM35 hanya untuk mendeteksi suhu dan kelemahan lainya yaitu penggunan limit swicth yang menjadi saklar utama sistem yaitu apabila limit swicth berada dalam posisi ON (pintu terbuka) maka sistem akan berjalan begitu sebaliknya. Hasil dari sistem ini masih berupa purwarupa (miniatur).

Penelitian untuk merancang-bangun sistem kontrol kipas angin dan lampu otomatis berbasis Arduino Uno R3 menggunakan multisensor di dalam ruang dibuat. Kipas angin dan lampu ruangan otomatis bekerja apabila ada orang di dalam ruangan dan berdasarkan kebutuhan di dalam ruangan tersebut. Sensor yang digunakan adalah sensor PIR, sensor suhu dan kelembaban DHT11, dan sensor LDR. Sensor PIR (Passive Infrared Receiver) merupakan sebuah sensor berbasiskan inframerah (Infrared). PIR tidak memancarkan apapun seperti IR LED. Sesuai dengan namanya 'Passive', sensor ini hanya merespon energi dari pancaran sinar inframerah pasif yang dimiliki oleh setiap benda. Sensor DHT11 adalah sensor yang dapat mengindra dua kondisi sekaligus yaitu suhu dan kelembaban, mudah dalam pengoperasian dimana pemasangan sensor yang memiliki 4 pin ini terdiri dari VCC, ground, masukan sensor serta NC (not connected), langsung dapat dihubungkan ke mikrokontroler Arduino Uno R3. LDR adalah singkatan dari Light Dependent Resistor yaitu salah satu jenis resistor yang dapat mengalami perubahan nilai resistansi apabila intensitas cahaya yang mengenainya berubah. Informasi mengenai ada atau tidak ada orang di ruangan, temperatur, kelembaban, intensitas cahaya, hidup atau matinya kipas angin dan lampu ditampilkan melalui LCD.

\section{METODE}

Metode yang digunakan dalam penelitian ini antara lain perancangan diagram blok sistem, perancangan sistem perangkat keras, perancangan bentuk fisik alat, perancangan skematik rangkaian (termasuk pemilihan komponen yang akan digunakan), perakitan komponen pada papan rangkaian tercetak (printed circuit board, $\mathrm{PCB}$ ) dan pengujian masing-masing blok rangkaian.perancangan perangkat lunak terdiri dari perancangan diagram alir program, penulisan program dalam bahasa pemograman $\mathrm{C}$ menggunakan sofware IDE (Integrated Development Environment) Arduino, dan penanaman (upload) ke papan Arduino.

\subsection{Perancangan Diagram Blok Sistem}

Diagram blok sistem merupakan alat bantu perancangan sistem secara global yang memperlihatkan sistem secara umum dan bagian-bagian dari sub sistem yang terlibat dalam 
sistem secara keseluruhan, keterkaitan dan interaksi antar subsistem. Diagram blok sistem terlihat seperti pada Gambar 1.

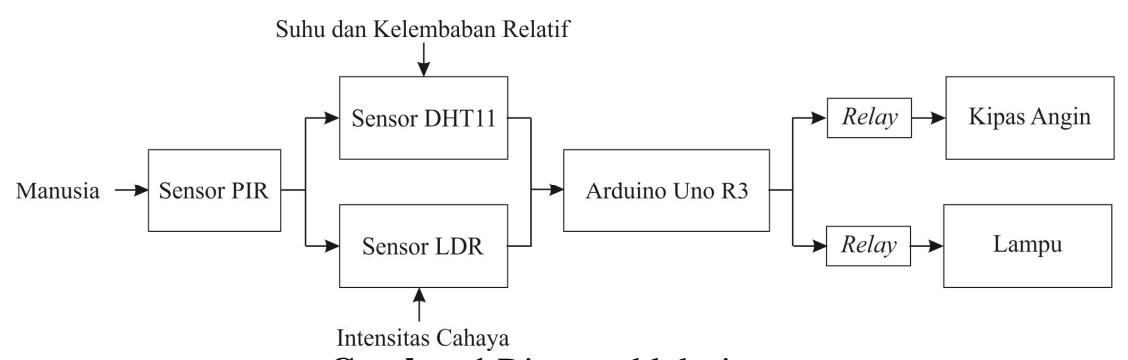

Gambar 1 Diagram blok sistem

Keberadan manusia dideteksi oleh sensor PIR selanjutnya sistem bekerja, sensor DHT11 mendeteksi suhu dan kelembaban di dalam ruangan. Apabila suhu di atas $27^{\circ} \mathrm{C}$ dan kelembaban di bawah $40 \%$ maka kipas angin menyala. Selanjutnya LDR mengukur intensitas cahaya di dalam ruangan, lampu menyala dengan menggunakan relay yang aktif apabila intensitas cahaya kurang dari 100 Lux. Segala informasi yang diindera oleh sensor ditampilkan di layar penampil LCD.

\subsection{Perancangan Sistem Perangkat Keras}

Pada perancangan sistem perangkat keras kipas angin dan lampu otomatis ini terdiri dari beberapa piranti elektronik yang terhubung langsung dengan mikrokontroler Arduino Uno R3 sebagai pusat pengolahan data yang berkaitan dengan input atau output sistem. Adapun piranti yang digunakan sebagai input adalah sensor PIR, sensor DHT11 dan sensor LDR. Sedangkan piranti output adalah LCD sebagai penampil dan relay sebagai saklar otomatis. Skematik rangkaian secara keseluruhan ditunjukan oleh Gambar 2.

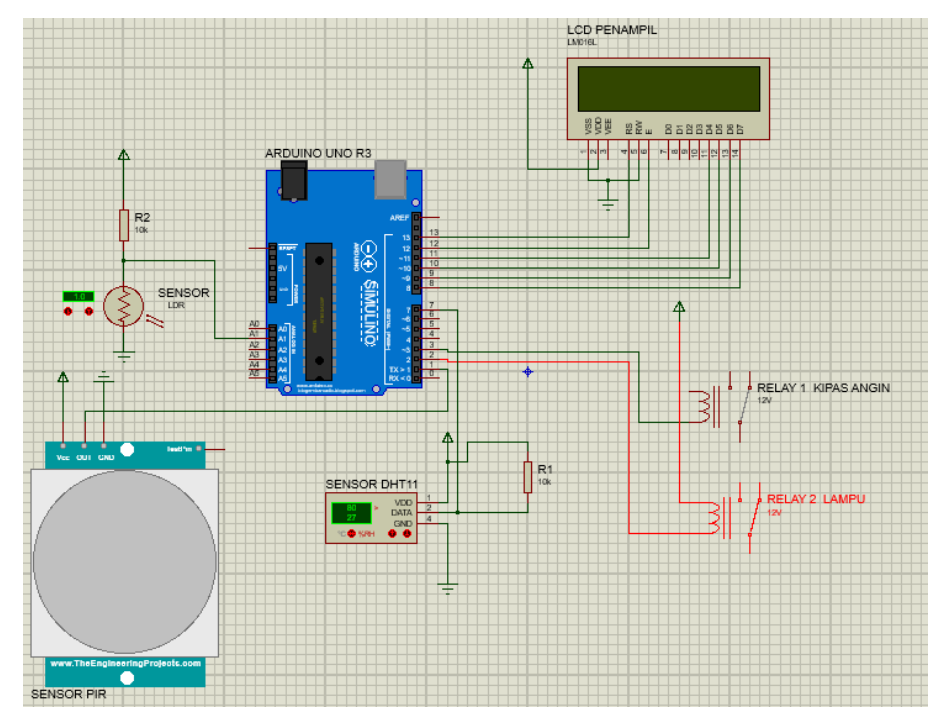

Gambar 2 Rangkaian sistem perangkat keras secara keseluruhan

\subsection{Perancangan Bentuk Fisik Alat}

Bentuk fisik alat dirancang dengan mempertimbangkan keefisienan dan kemudahan dalam menggunakan alat. Penempatan alat kontrol di dalam ruangan juga diperhatikan dimana posisi alat berada di depan pengguna ruangan atau masih berada dalam jangkauan sensor PIR sebagai sensor utama yang mendeteksi pergerakan manusia. Penempatan alat kontrol dapat dilihat pada Gambar 3. 


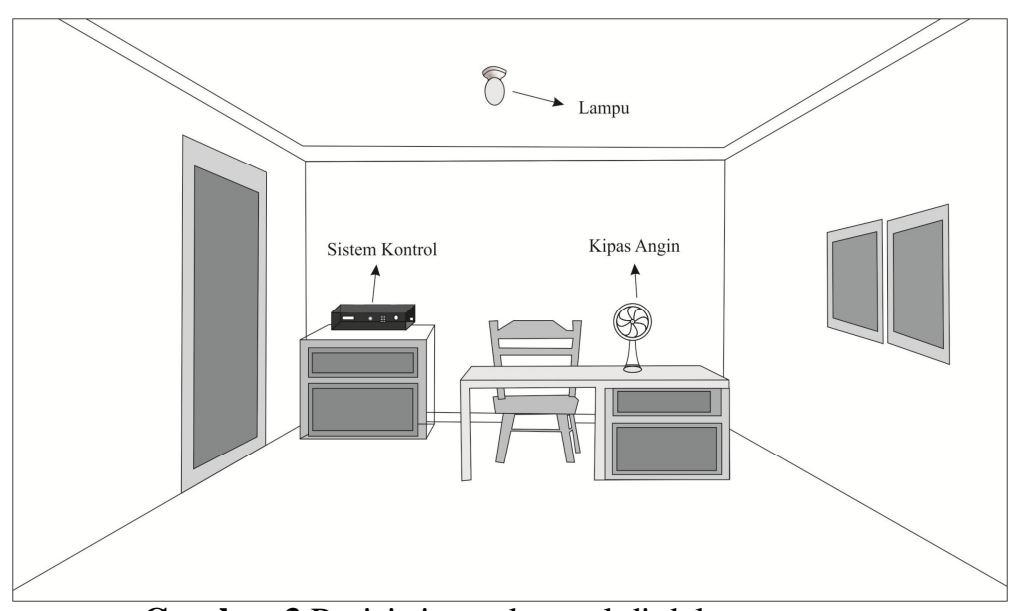

Gambar 3 Posisi sistem kontrol di dalam ruangan

Pada Gambar 3 dapat dilihat bahwa sensor PIR dipasang tepat di depan pengguna beraktifitas di dalam ruangan. Sensor DHT11 juga dipasang pada posisi yang sama dengan tujuan memudahkan sensor mendeteksi kondisi temperatur dan kelembaban relatif di dalam ruangan. Sensor LDR di pasang menghadap ke sumber cahaya alami di dalam ruangan yaitunya jendela dengan tujuan apabila cahaya alami yang diterima ruangan sudah cukup yaitu di atas 100 Lux maka lampu tidak perlu dihidupkan.

\subsection{Diagram Alir}

Diagram alir perangkat lunak pada Arduino Uno R3 dimulai dengan sensor PIR mendeteksi ada atau tidaknya orang di dalam ruangan, kemudian apabila ada orang di dalam ruangan sensor DHT11 bekerja mendeteksi temperatur dan kelembaban di dalam ruangan. Apabila hasil pendeteksian temperatur di atas $27^{\circ} \mathrm{C}$ atau kelembaban berada di atas $40 \%$ seperti yang telah ditanamkan di dalam program maka kipas angin hidup. Untuk intensitas cahaya, apabila sensor LDR mendeteksi cahaya di bawah 100 Lux atau di bawah 500 ADC maka lampu ruangan otomatis hidup. Untuk diagram alir sistem secara keseluruhan dapat dilihat pada Gambar 4.

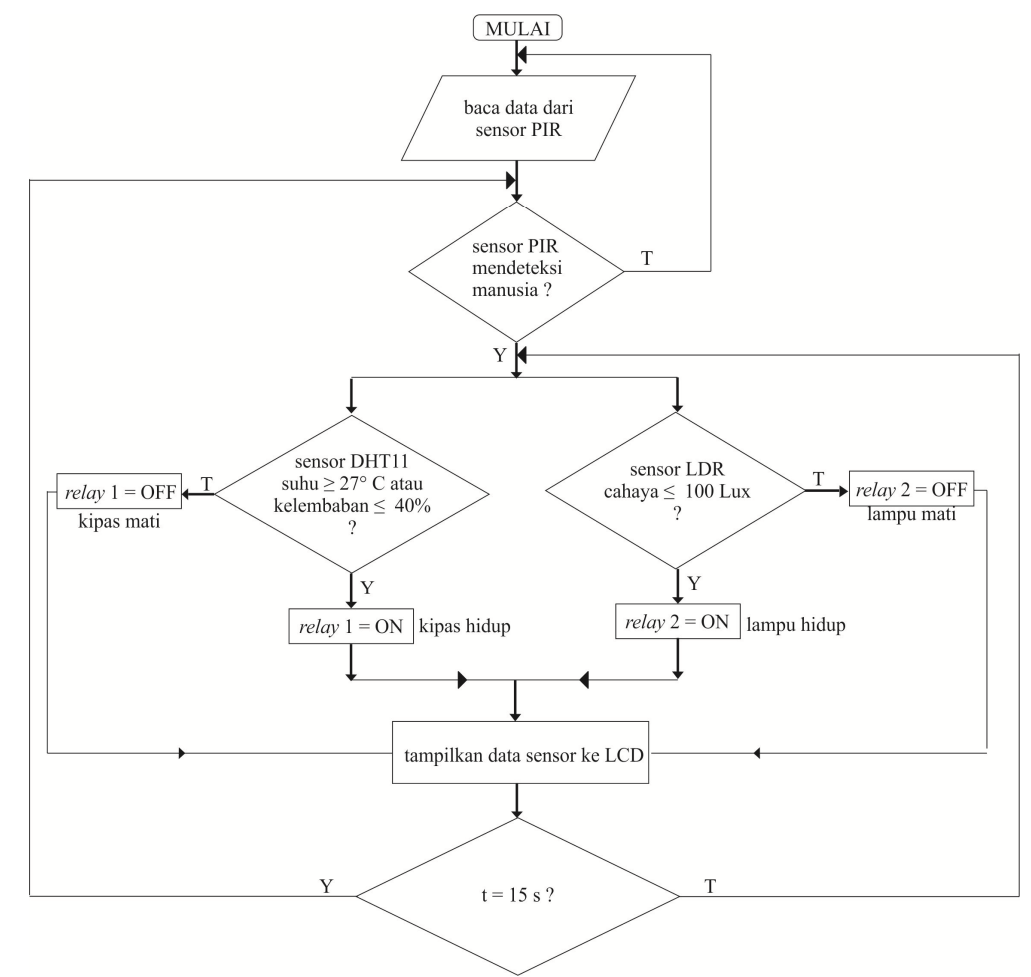

Gambar 4 Diagram alir 
Sensor PIR dipasang di depan alat secara keseluruhan, dengan tujuan mendeteksi keberadaan manusia terlebih dahulu. Apabila sensor PIR telah mendeteksi manusia di dalam ruangan maka sensor yang lain bekerja.

\section{HASIL DAN DISKUSI}

\subsection{Karakterisasi Sudut Jangkauan Sensor PIR}

Karakterisasi sudut jangkauan sensor PIR HC-SR501 diperlukan untuk mengetahui jarak maksimum yang dapat dijangkau sensor PIR tersebut dalam mendeteksi suatu objek. Pengujian dilakukan dengan cara objek diletakan dengan variasi sudut $0^{\circ}, 30^{\circ}, 60^{\circ}, 70^{\circ}$, dan $80^{\circ}$ secara horizontal terhadap sensor dan jarak yang juga divariasikan antara $1 \mathrm{~m}$ sampai dengan 7 m. Hasil pengujian ini diperlihatkan pada Tabel 1.

Tabel 1 Karakterisasi Sudut Jangkauan Sensor PIR

\begin{tabular}{lcccccccc}
\hline \multirow{2}{*}{ No } & \multirow{2}{*}{ Sudut } & $\mathbf{1 m}$ & $\mathbf{2 m}$ & $\mathbf{3 m}$ & $\mathbf{4 m}$ & $\mathbf{5 m}$ & $\mathbf{6 m}$ & $\mathbf{7 m}$ \\
\hline 1. & $0^{\circ}$ & $\mathrm{V}$ & $\mathrm{V}$ & $\mathrm{V}$ & $\mathrm{V}$ & $\mathrm{V}$ & $\mathrm{V}$ & $\mathrm{X}$ \\
2. & $30^{\circ}$ & $\mathrm{V}$ & $\mathrm{V}$ & $\mathrm{V}$ & $\mathrm{V}$ & $\mathrm{V}$ & $\mathrm{X}$ & $\mathrm{X}$ \\
3. & $60^{\circ}$ & $\mathrm{V}$ & $\mathrm{V}$ & $\mathrm{V}$ & $\mathrm{X}$ & $\mathrm{X}$ & $\mathrm{X}$ & $\mathrm{X}$ \\
4. & $70^{\circ}$ & $\mathrm{X}$ & $\mathrm{X}$ & $\mathrm{X}$ & $\mathrm{X}$ & $\mathrm{X}$ & $\mathrm{X}$ & $\mathrm{X}$ \\
5. & $80^{\circ}$ & $\mathrm{X}$ & $\mathrm{X}$ & $\mathrm{X}$ & $\mathrm{X}$ & $\mathrm{X}$ & $\mathrm{X}$ & $\mathrm{X}$ \\
\hline \multicolumn{2}{l}{ Keterangan : } & V $=$ Terdeteksi & & & & \\
& & $\mathrm{X}=$ Tidak Terdeteksi & & & & &
\end{tabular}

Hasil pengujian menunjukan bahwa sudut maksimum agar radiasi inframerah dari objek dapat dideteksi oleh sensor adalah dari sudut $0^{\circ}$ sampai sudut $60^{\circ}$ baik ke sisi kiri maupun kanan sensor. Sedangkan jarak maksimum yang mampu dideteksi sensor adalah $6 \mathrm{~m}$ pada sudut $0^{\circ}$ atau tepat lurus di depan sensor. Hal ini sedikit berbeda dengan datasheet yang menyatakan jangkauan maksimum sensor mencapai $7 \mathrm{~m}$. Untuk sudut $30^{\circ}$ dan $60^{\circ}$ jarak maksimum yang terdeteksi adalah $5 \mathrm{~m}$ dan $3 \mathrm{~m}$ dari sensor.

\subsection{Karakterisasi Sensor DHT11}

Sensor DHT11 diuji keakuratan pengukurannya dengan menggunakan alat pembanding humidity/thermometer type $k$ Lutron HT-3006HA yang memiliki kemampuan pengukuran temperatur dan kelembaban. Data yang diperoleh dihitung nilai \% errornya. Hasil pengujian dan pengukuran sensor DHT11, Lutron HT-3006HA, dan \% errornya dapat dilihat pada Tabel 2.

Tabel 2 Karakterisasi Sensor DHT11

\begin{tabular}{|c|c|c|c|c|c|c|}
\hline \multirow[b]{2}{*}{ No. } & \multicolumn{2}{|c|}{ Sensor DHT11 } & \multicolumn{2}{|c|}{ Lutron HT-3006HA } & \multicolumn{2}{|c|}{$\%$ Error } \\
\hline & $\begin{array}{l}\text { Temperatur } \\
\left({ }^{\circ} \mathrm{C}\right)\end{array}$ & $\begin{array}{c}\text { Kelembaban } \\
(\%)\end{array}$ & $\begin{array}{c}\text { Temperatur } \\
\left({ }^{\circ} \mathrm{C}\right)\end{array}$ & $\begin{array}{c}\text { Kelembaban } \\
(\%)\end{array}$ & Temperatur & Kelembaban \\
\hline 1. & 25 & 90 & 25,3 & 86,1 & 1,19 & 4,53 \\
\hline 2. & 25 & 87 & 25,4 & 82,0 & 1,57 & 6,06 \\
\hline 3. & 25 & 87 & 25,3 & 83,8 & 1,19 & 3,80 \\
\hline 4. & 26 & 66 & 25,3 & 76,3 & 2,77 & 13,50 \\
\hline 5. & 26 & 76 & 25,6 & 84,0 & 1,57 & 9,52 \\
\hline 6. & 27 & 72 & 28,2 & 77,7 & 5,32 & 7,33 \\
\hline 7. & 28 & 71 & 28,6 & 76,7 & 2,02 & 7,43 \\
\hline 8. & 29 & 67 & 28,9 & 65,2 & 0,34 & 2,77 \\
\hline 9. & 29 & 66 & 29,2 & 67,1 & 0,69 & 1,63 \\
\hline 10. & 29 & 65 & 29,6 & 67,2 & 2,02 & 3.28 \\
\hline \multicolumn{5}{|c|}{ Rata-rata persen error } & 1,87 & 5,98 \\
\hline
\end{tabular}

Dari Tabel 2 dapat dilihat bahwa sensor DHT11 memiliki nilai kemampuan pengukuran hanya sebatas bilangan bulat berbeda dengan alat pembanding humidity/thermometer type $k$ Lutron HT-3006HA yang memiliki kemampuan pengukuran temperatur dan kelembaban 
dengan nilai desimal 1 angka dibelakang koma. Sehingga secara keakuratan alat pembanding jauh lebih baik dibandingkan sensor yang digunakan. Nilai yang diperoleh secara umum juga cukup berbeda terutama di pengukuran kelembaban dengan rata-rata persentase errornya 5,98 $\%$, sedangkan untuk nilai pengukuran temperatur menggunakan sensor DHT11 hasilnya mendekati nilai yang terukur oleh alat pembanding dengan nilai error sebesar $1,87 \%$. Pada pengukuran pertama dilakukan pagi hari sekitar pukul 09.00 WIB dengan kondisi cuaca cerah diperoleh nilai temperatur dan kelembaban dengan sensor DHT11 adalah $26{ }^{\circ} \mathrm{C}$ dan $66 \%$ kelembaban, sedangkan pada alat pembanding diperoleh nilai $25,6^{\circ} \mathrm{C}$ dan kelembaban $76,3 \%$. Untuk data selanjutnya temperatur yang didapatkan lebih rendah hanya sekitar $25^{\circ} \mathrm{C}$ karena meskipun pengukuran dilakukan siang hari kondisi cuaca siap hujan dan masih gerimis sehingga kelembaban yang terukur tinggi yaitu diatas $80 \%$. Untuk data selanjutnya di ambil dalam waktu yang acak antara siang hari dengan kondisi yang cerah sampai sore hari dengan kondisi yang mendung. Hal ini dilakukan untuk melihat variasi perbedaan temperatur dan kelembaban yang terukur oleh sensor DHT11 dengan dibandingkan dengan alat ukur humidity/thermometer type $k$ Lutron HT-3006HA, sehingga secara keseluruhan dapat disimpulkan sensor DHT11 dapat digunakan sebagai sistem kontrol untuk kipas angin.

\subsection{Karakterisasi Sensor LDR}

Pengujian sensor LDR dilakukan dengan memaparkan sensor secara langsung pada keadaan cahaya alami di dalam ruangan dari waktu ke waktu dengan kondisi cuaca normal. Ruangan yang digunakan pada pengujian ini adalah koperasi fisika Universitas Andalas yang memiliki 2 buah jendela kaca dengan posisi yang cukup tinggi dan sebuah pintu keluar samping dan pintu utama. Pencahayaan alami yang masuk ke dalam ruangan ini kurang baik. Dari pengujian ini kemudian dapat dilihat nilai-nilai ADC dari sensor LDR dan perbandingannya dengan alat ukur intensitas cahaya Lux meter. Pengukuran ini perlu dilakukan untuk melihat pada rentang nilai desimal ADC berapa saja dibutuhkan cahaya tambahan (lampu) untuk mengoptimalkan penerangan di dalam ruangan. Hasil pengukurannya dapat dilihat pada Tabel 3.

Tabel 3 Karakterisasi Sensor DHT11

\begin{tabular}{cccc}
\hline Waktu & Jam & $\begin{array}{c}\text { Nilai } \\
\text { Desimal ADC } \\
\text { LDR (ADC) }\end{array}$ & $\begin{array}{c}\text { Intensitas } \\
\text { Cahaya } \\
\text { (LUX) }\end{array}$ \\
\hline \multirow{2}{*}{ Pagi } & 05.00 & 68 & 0,0 \\
& 06.00 & 79 & 0,0 \\
Siang & 07.00 & 90 & 0,0 \\
& 12.00 & 393 & 20,5 \\
Sore & 13.00 & 518 & 42,3 \\
& 14.00 & 572 & 49,6 \\
& 16.00 & 185 & 1,89 \\
Malam & 17.00 & 125 & 0,00 \\
& 18.00 & 91 & 0,00 \\
& 19.00 & 70 & 0,00 \\
& 20.00 & 67 & 0,00 \\
& 21.00 & 66 & 0,00 \\
\hline
\end{tabular}

Dari Tabel 3 dapat dilihat bahwa nilai pencahayan di dalam ruangan sangat rendah dimana pada saat siang hari nilai lux yang terukur adalah maksimal 49,6 Lux, hal ini tentu sangat jauh dari standart yaitu 100 Lux (SNI 03-6197-2000). Sehingga untuk ruangan yang digunakan pada penelitian ini yaitu ruang koperasi fisika Universitas Andalas lampu dibutuhkan hidup setiap ada orang yang ingin menggunakan ruangan tersebut.

\subsection{Hasil Pengujian Sistem Secara Keseluruhan}

Setelah dilakukan pengujian pada masing-masing perangkat input dan output maka dilakukan pengujian sistem secara keseluruhan dan dilihat apakah perangkat input dan output 
yang digunakan bekerja dengan baik atau tidak. Hasil pengujian sistem secara keseluruhan dapat dilihat pada Tabel 4.

Tabel 4 Pengujian Sistem Secara Keseluruhan

\begin{tabular}{|c|c|c|c|c|c|c|}
\hline \multirow{2}{*}{ No. } & \multirow{2}{*}{$\begin{array}{l}\text { Sensor } \\
\text { PIR }\end{array}$} & \multicolumn{2}{|c|}{ Sensor DHT11 } & \multirow{2}{*}{$\begin{array}{c}\text { Relay } 1 \\
\text { (Kipas Angin) }\end{array}$} & \multirow{2}{*}{$\begin{array}{l}\text { Sensor } \\
\text { LDR }\end{array}$} & \multirow{2}{*}{$\begin{array}{c}\text { Relay } 2 \\
(\text { Lampu })\end{array}$} \\
\hline & & Temperatur $\left({ }^{\circ} \mathrm{C}\right)$ & Kelembaban (\%) & & & \\
\hline 1. & A & - & - & OFF & - & OFF \\
\hline 2. & B & 30 & 67 & ON & 411 ADC & ON \\
\hline 3. & B & 27 & 73 & ON & $185 \mathrm{ADC}$ & ON \\
\hline 4. & B & 25 & 87 & OFF & $125 \mathrm{ADC}$ & ON \\
\hline 5. & B & 25 & 90 & OFF & $91 \mathrm{ADC}$ & ON \\
\hline
\end{tabular}

Keterangan : $\quad$ kondisi $\mathrm{A}=$ tidak ada orang di dalam ruangan

kondisi $\mathrm{B}=$ ada orang di dalam ruangan

Pada Tabel 4.6 dapat dilihat bahwa kipas angin dan lampu dapat bekerja dengan baik dimana pada saat tidak ada orang di dalam ruangan kipas angin (relay 1) dan lampu (relay 2) tidak hidup dan juga informasi mengenai temperatur, kelembaban, dan nilai ADC dari sensor LDR tidak ditampilkan. Pada saat ada orang di dalam ruangan sensor DHT11 bekerja dengan baik mendeteksi temperatur dan kelembaban ruangan, dimana pada saat temperatur $30{ }^{\circ} \mathrm{C}$ dengan kelembaban $67 \%$ maka kipas angin hidup (relay 1 ON). Begitu juga pada saat temperatur terdeteksi $27{ }^{\circ} \mathrm{C}$ dengan kelembaban $73 \%$ kipas angin juga hidup. Pada saat temperatur terdeteksi $25{ }^{\circ} \mathrm{C}$ dengan kelembaban $87 \%$ dan $90 \%$ kipas angin mati (relay $2 \mathrm{OFF}$ ), hal ini karena temperatur acuan yang ditanamkan pada program adalah pada temperatur di atas $27{ }^{\circ} \mathrm{C}$ dan kelembaban di bawah $40 \%$. Pada saat ada orang di dalam ruangan sensor LDR juga bekerja dengan baik, dimana semua nilai ADC yang terdeteksi adalah di bawah 500 sehingga lampu hidup (relay $2 \mathrm{ON}$ ). Hal ini disebabkan oleh ruangan yang digunakan tidak memiliki sistem pencahayaan alami yang baik sehingga setiap ada orang di dalam ruangan lampu hidup.

\section{KESIMPULAN}

Sistem keseluruhan alat dapat bekerja apabila ada orang di dalam ruangan. Lampu hidup apabila intensitas cahaya di bawah 500 ADC. Kipas angin hidup apabila temperatur di atas $27{ }^{\circ} \mathrm{C}$ atau kelembaban relatif di bawah $40 \%$. Sensor PIR yang digunakan untuk mendeteksi objek manusia di dalam ruangan dapat bekerja dengan rentang sudut $120^{\circ}$, yaitu $60^{\circ}$ ke kiri dan $60^{\circ}$ ke kanan sumbu vertikal sensor. Jarak maksimum 6 m posisi tepat di depan sensor, jarak jangkauan sensor berkurang dengan penambahan sudut posisi objek terhadap sensor. Sensor DHT11 dapat mendeteksi perubahan temperatur dan kelembaban di dalam ruangan dengan error pengukuran temperatur rata-rata $1,87 \%$ dan error pengukuran kelembaban relatif $5,98 \%$. Sensor LDR dapat mendeteksi perubahan intensitas cahaya di dalam ruangan.

\section{DAFTAR PUSTAKA}

Desyantoro, E., Rochim, A.F., dan Martono, K.T., "Sistem Pengendali Peralatan Elektronik Dalam Rumah Secara Otomatis Menggunakan Sensor PIR, Sensor LM35, dan Sensor LDR",Skripsi S1, Universitas Diponegoro,2015.

Kurniawan, E., Suhery, C., dan Triyanto, D., "Sistem Penerangan Rumah Otomatis dengan Sensor Cahaya Berbasis Mikrokontroler", Skripsi S1, Universitas Tanjungpura, 2013.

PLN, "Rencana Usaha Penyediaan Tenaga Listrik PT PLN (Persero) 2015-2024”, Jakarta, 2015.

Republik Indonesia, "Instruksi Presiden Republik Indonesia nomor 10 tahun 2005 tentang penghematan energi", Sekretariat Negara, Jakarta, 2005.

Otomo, G., dan Wildian, "Sistem Kontrol Penyalaan Lampu Ruang Berdasarkan Pendeteksian Ada Tidaknya Orang Di Dalam Ruangan”, Skripsi S1, Universitas Andalas, 2013. 